\title{
CLASIFICACION ULTRASONOGRAFICA DE LOS DESGARROS MUSCULARES
}

\section{Dr. Marco Antonio Verdugo P.}

Centro Radiológico Fleming. Departamento de Imágenes, Centro MEDS

\begin{abstract}
Muscle tears are frequent lesions in sports and are of special importance when present in professional sportsmen. Ultrasound has been proved to be a very useful tool in the diagnosis and characterization of these lesions, in the base of standard patterns which we have observed throughout the years. The known clasification in grades 1,2 y 3 has no useful utilization, at least in our country.

We propose, then, a new clasification based in the type and ubication of these lesions (qualitative aspects), plus its meassurement (quantitative aspect), which has been proved to be of great utility in their therapeutic management.
\end{abstract}

Key words: Muscle tears, Ultrasonographic clasification.

Resumen: Los desgarros musculares son lesiones frecuentes en la práctica deportiva y conllevan especial importancia cuando se trata de deportistas profesionales. El ultrasonido ha demostrado ser una herramienta de diagnóstico muy eficaz en el diagnóstico y caracterización de estas lesiones, en base a patrones más o menos característicos que hemos observado en nuestra experiencia. La clasificación anglosajona en grado 1,2 y 3, no tiene mayor utilidad práctica, al menos en nuestro país.

Se propone, una clasificación basada en el tipo y ubicación de estas lesiones (aspecto cualitativo), sumado a la medición (aspecto cuantitativo), que ha demostrado utilidad para el manejo terapéutico.

Palabras claves: Clasificación ultrasonográfica. Desgarros musculares.

Verdugo MA. Clasificación ultrasonográfica de los desgarros musculares. Rev Chil Radiol 2004; 10: 53-57. Correspondencia: Dr. Marco A. Verdugo P.

E-mail:marver@manquehue.net

\section{Introducción}

El ultrasonido de alta resolución (US) se ha convertido, en el método de elección en la evaluación de los desgarros musculares, en nuestro país y en muchos otros del mundo, especialmente en aquellos donde el fútbol es el deporte principal como ocurre en Argentina, España, Italia y otros. Además de su uso en la etapa diagnóstica, es útil para el seguimiento de estas lesiones y por tanto, para decidir el retorno a la actividad deportiva ${ }^{(1-6)}$.

Es fundamental una evaluación cuidadosa y lo más acertada posible de la lesión muscular, ya que de ello depende la terapia a instaurar, tiempo de tratamiento y retorno a la actividad deportiva. Estos hechos cobran especial relevancia cuando se trata de deportistas profesionales, en que el período de ausentismo de la actividad conlleva necesariamente perjuicios económicos.

La clasificación de los desgarros musculares en grados 1,2 y 3 , propuesta en la literatura anglosajona ${ }^{(6)}$ adolece de serias fallas en cuanto a la caracterización de las lesiones, su tamaño y tampoco ofrece un factor pronóstico. Más aún, es demasiado simplista y difícil de aceptar por los especialistas, en medicina deportiva y kinesiólogos, en el momento de instaurar una terapia. Durante años de práctica ultrasonográfica en este tipo de lesiones hemos observado que se repiten ciertos patrones característicos de desgarros musculares, en ubicaciones bastante precisas, constatando además que existe una relación estrecha entre el grado de preparación física del deportista y el tipo de desgarros. Sobre la base de lo anterior surgió una clasificación ultrasonográfica, que considera cualitativamente el tipo de desgarro definiendo un pronóstico de gravedad y tiempo de curación. Agregamos a lo anterior la evaluación cuantitativa efectuando la medición de la lesión.

Se propone, esta clasificación con el fin de uniformar criterios y facilitar el entendimiento entre 
clínicos y radiólogos. Probablemente adolezca de fallas, no obstante, en nuestra experiencia ha demostrado con creces su utilidad. No están incluidas las laceraciones o atriciones musculares provocadas por agentes externos, ni lesiones relacionadas directamente con la práctica deportiva que suelen confundirse con desgarros, entre las cuales están los llamados síndromes de dolor muscular retardado y compartimentales, patología en estrecha relación con la sobrecarga de ejercicio. No es tampoco el propósito de este artículo referirse a la ultraestructura y anatomía muscular, o tipos de fibras musculares, elementos todos que han sido destacados en otras publicaciones $^{(1-6)}$

Es necesario tener presente que cualquier traumatismo muscular generará algún grado de daño y edema. Este último es fácilmente objetivable en todos los casos de desgarro y otros traumas musculares, pero, en ocasiones, puede ser el único elemento visible a la ultrasonografía o resonancia magnética ${ }^{(7-9)}$.

El edema como hallazgo único puede presentarse en dos situaciones. En la primera no hay daño estructural, solo alguna alteración en la fisiología muscular y acumulación de metabolitos que generan cambios celulares en todo el área muscular, la segunda es que exista compromiso anatómico de pequeña magnitud no objetivable por los métodos de imagen. Cualquiera sea la situación, estas condiciones suelen relacionarse con dos eventos clínicos, el primero corresponde a la llamada "contractura" muscular, en la cual el examen puede ser completamente negativo o objetivarse solo la presencia de edema muscular hecho que se correlaciona con una evolución clínica favorable, o bien en otros casos puede existir edema provocado por síndromes de sobrecarga, cuya significación es más trascendente.

En la ultrasonografía el edema se presenta como un área relativamente mal definida de hiperecogenicidad con aumento de volumen (Figura 1).

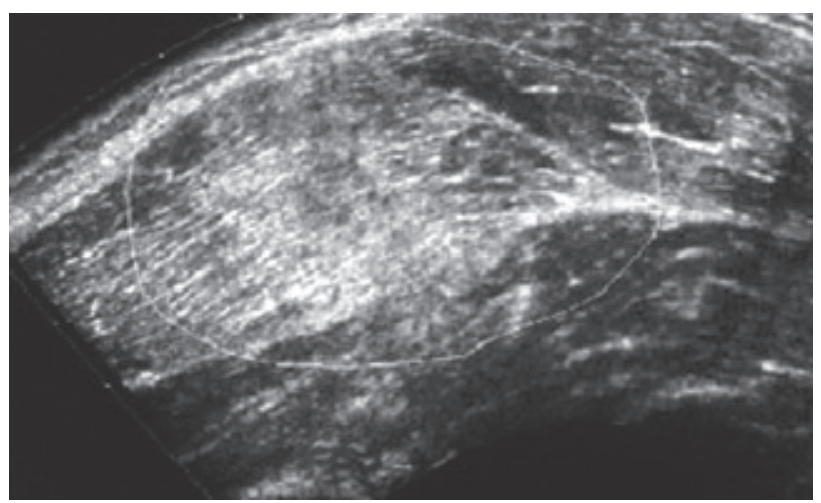

Figura 1. Corte transversal extendido del músculo cuadriceps demostrando edema como un área hiperecogénica (trazo ovalado) sin daño estructural asociado.

\section{Clasificación de los desgarros musculares}

Nuestra clasificación comprende seis tipos diferentes de desgarros considerando sus características: 1) Desgarro miofascial, 2) Desgarro Fibrilar, 3) Desgarro Multifibrilar, 4) Desgarro Fascicular, 5) Desgarro masivo o total con o sin avulsión ósea, 6) Adherenciolisis.

1) Desgarro miofascial. Comprende dos elementos anatómicos, la fascia o aponeurosis y, las fibras musculares periféricas. Es una lesión de muy buen pronóstico y suele curar sin secuelas en un tiempo relativamente corto que va entre los 15-25 días. Se trata de una solución de continuidad de la fascia muscular, la cual pierde su contorno nítido y se acompaña de bandas laminares de fluido hipoecogénicas con separación y cierta retracción de las fibras musculares periféricas. Según la magnitud de la lesión, puede acompañarse de mayor o menor grado de colección fusiforme perilesional y subaponeurótica. Siempre hay edema periférico de fibras musculares, que al ultrasonido se observará como áreas hiperecogénicas, en un radio que dependerá de la cuantía de la lesión (Figura 2).

Este tipo de desgarro es el más frecuente en los deportistas profesionales de alto rendimiento y puede recidivar fácilmente si es reintegrado a la práctica antes de la cicatrización total.

Los sitios más frecuentes son: Isquiotibiales (semitendinoso en sus tercios proximal y medio y biceps crural en su porción larga distal a nivel de la unión miotendínea) y triceps sural (gemelo interno, porción distal y medial).

Esta lesión puede pasar fácilmente inadvertida o subestimada sino se efectúa un examen cuidadoso. Con respecto a la cuantía, se hablará de un desgarro pequeño cuando comprometa un segmento de hasta $3 \mathrm{~cm}$, con escaso compromiso de fibras musculares y finas láminas de fluido, moderado cuando mide entre 3 y $6 \mathrm{~cm}$, más aún si se acompaña de una pequeña colección subaponeurótica o perifascial. Sobre los $6 \mathrm{~cm}$ se estima un desgarro de una cuantía importante.

2) Desgarro fibrilar. Generalmente es una lesión de tipo lineal muy fina, de ahí su nombre, con una longitud variable, pero con un grosor que no debería exceder los $2 \mathrm{~mm}$. Ocurre en el espesor de la musculatura, se acompañan de edema perilesional de cuantía variable y su pronóstico es muy bueno, cicatrizando sin secuelas.

Al igual que el desgarro miofascial, ocurre mas frecuentemente en deportistas entrenados. Afecta cualquier músculo, pero es más frecuente en isquiotibiales y cuadriceps, muy raro en el tríceps sural.

El aspecto ultrasonográfico consta de un defecto hipoecogénico fino, en un contexto de edema hiperecogénico circundante, a veces con aumento 

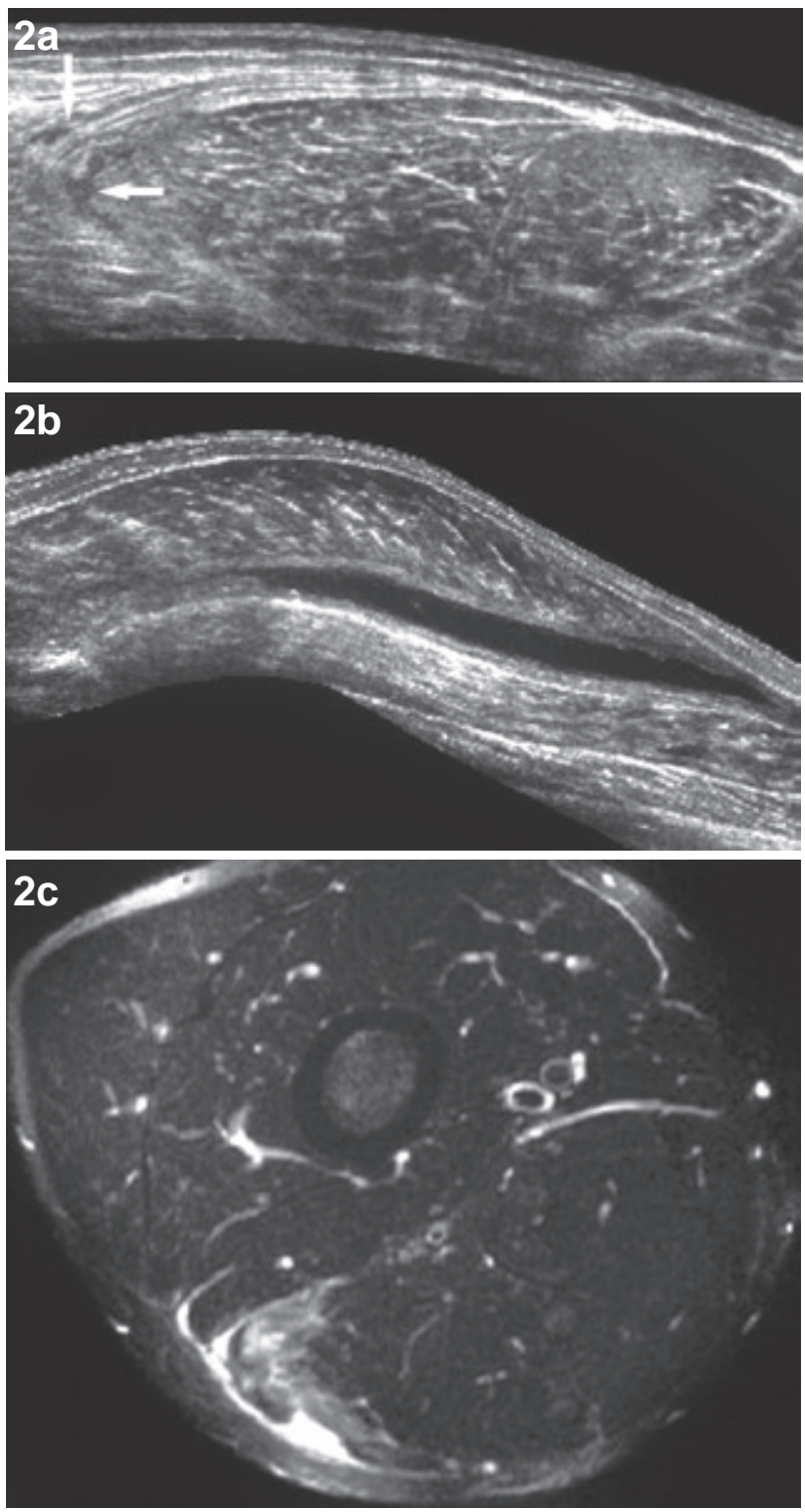

Figura 2 a-c. Desgarro miofascial. a: Compromiso del recto anterior del cuadriceps derecho. Corte transversal extendido. Hay engrosamiento y borramiento del contorno externo del músculo además de varias finas bandas laminares de fluido hemático (flechas). $b$ : Compromiso extenso del gemelo interno con colección fusiforme hipoecogenica entre este y el sóleo. Corte longitudinal extendido Esta lesión puede asociarse con rotura del plantar delgado. c: RM, secuencia T2 con supresión grasa que demuestra un típico desgarro miofascial del bíceps crural. Obsérvese la presencia de edema muscular y colección perimuscular laminar visible como señal hiperintensa.

de volumen local. Suelen ser lesiones con poca extensión, no mas de 3 a $4 \mathrm{~cm}$ en longitud, lo cual es una cuantía leve (Figura 3). Mayores desgarros se acompañan de lesiones adicionales y están fuera de esta caracterización.

3) Desgarro multifibrilar. Variante del anterior, de mayor importancia clínica. Consta de varias soluciones de continuidad lineales, generando un
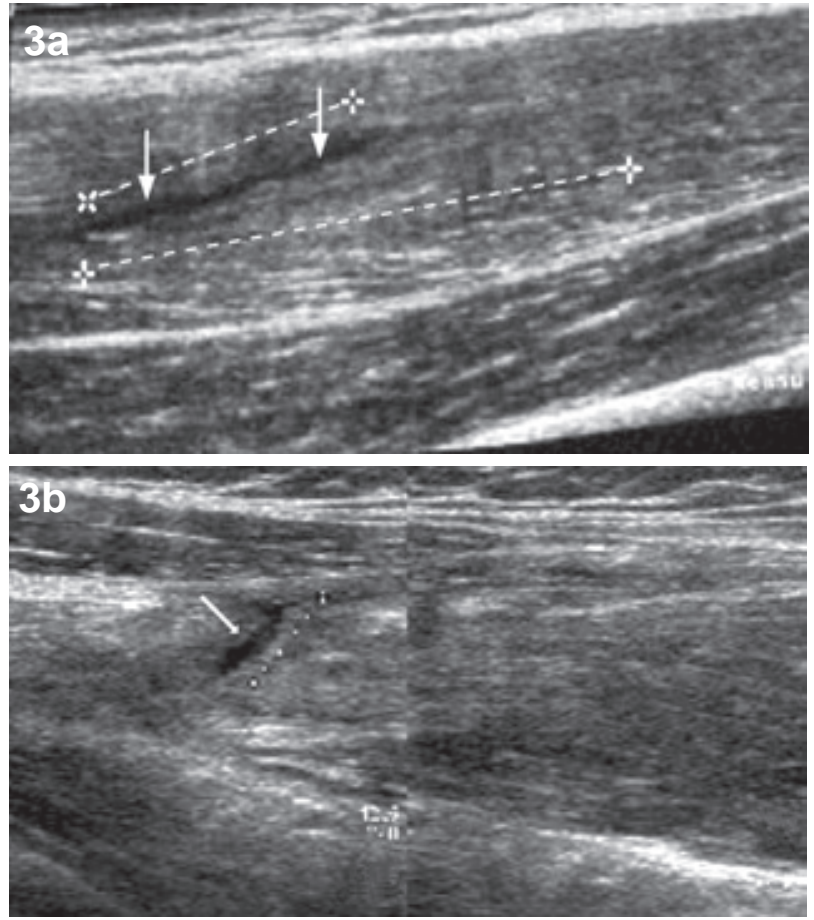

Figura 3 a,b. Dos diferentes ejemplos de desgarro fibrilar con compromiso del cuadriceps (flechas). Corte longitudinal extendido (a) e imagen compuesta (b). Nótese lo preciso de la lesión, cuyo espesor no supera los $2 \mathrm{~mm}$.

foco lesional de mayor tamaño y, asociado a edema de mayor extensión e intensidad. Su pronóstico sigue siendo bueno, pero requiere de un mayor tiempo de curación. Pueden dejar pequeñas cicatrices retráctiles. Estas lesiones se ven indistintamente en deportistas entrenados y aficionados. Probablemente el sitio de ocurrencia más común es el músculo recto anterior del cuadriceps.

El aspecto al ultrasonido es similar al fibrilar, con la diferencia que se presenta como varios defectos lineales hipoecogénicos. Se acompañan de un mayor grado de edema. Se consideran de cuantía moderada desde los 3-4 cms, hacia arriba, ya que cuando la cuantía es leve generalmente se trata de desgarros fibrilares (Figura 4).

4) Desgarro fascicular. Es una lesión de mayor trascendencia, puede ocurrir en el espesor del músculo o en su periferia, donde se acompañan de compromiso fascial, con colección hemática asociada de variable cuantía y, clínicamente aparición de equimosis. El desgarro fascicular del músculo mismo suele ser bien definido, como un defecto hipoecogénico de 3 o más $\mathrm{cm}$. de espesor, de longitud variable. El lecho de la rotura se acompaña de una colección hemática que ocasionalmente puede ser de mayor tamaño por efecto expansivo con compresión del músculo adyacente. Son lesiones de cuantía moderada que miden aproximadamente $3 \times 3 \mathrm{cms}$. en espesor y longitud hacia arriba. Las lesiones periféricas con 

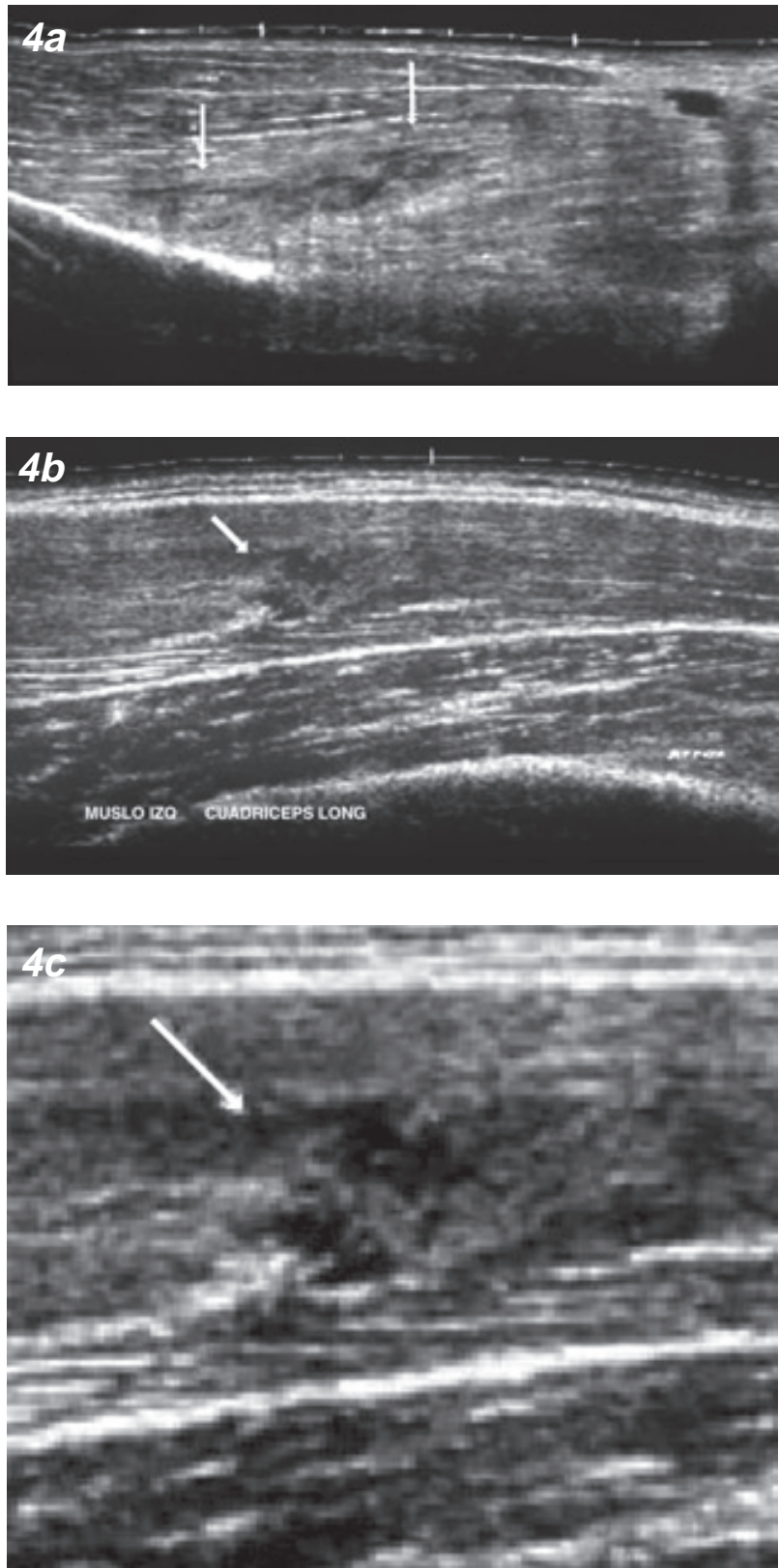

Figura 4 a-c. Desgarro multifibrilar. a: Compromiso poco frecuente en el braquial anterior. Hay varias lesiones lineales o fibrilares (flechas) configurando una amplia área de lesión con edema. $b$ : Compromiso similar del cuadriceps (flecha). c: Ampliación del área de interés en b.

compromiso de la fascia suelen ser de mayor tamaño y se consideran de cuantía importante. En estos casos el período de cicatrización puede tomar mas de un mes (Figura 5).

5) Desgarro total. Obviamente son todas lesiones graves que dejaran algún grado de pérdida de la función, desbalances musculares y grandes cicatrices. Comprenden desde un grueso segmento hasta todo el espesor del músculo. Se incluyen aquí
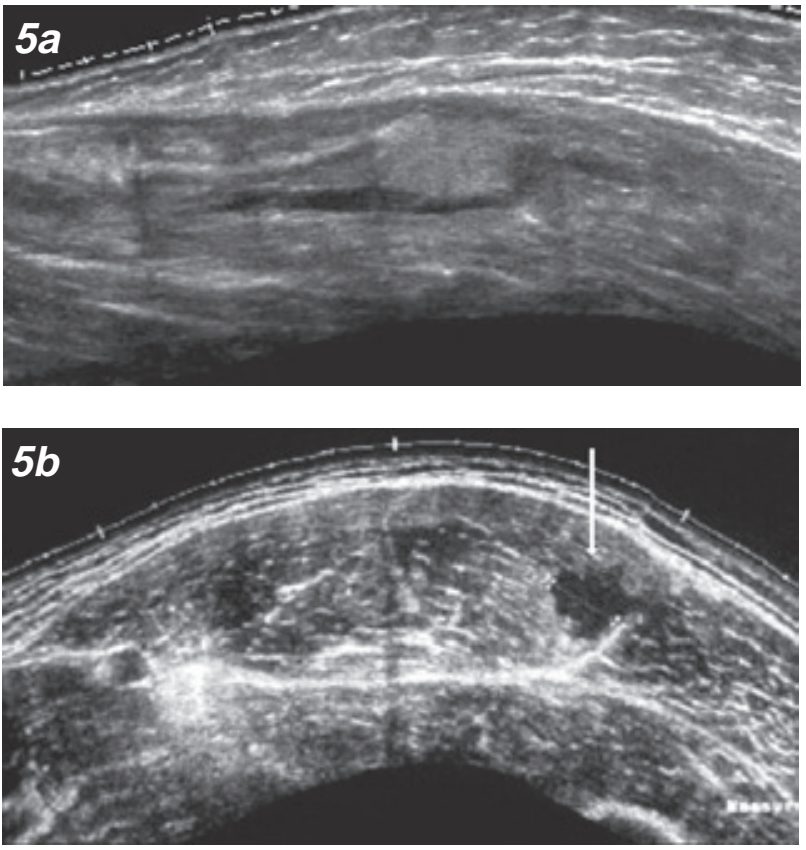

Figura 5 a,b. a: Grueso desgarro fascicular de los aductores. La lesión mide mas de $2 \mathrm{~mm}$ de espesor y aproximadamente $7 \mathrm{cms}$ en longitud Distorsión del patrón muscular circundante por edema. b: Corte transversal del cuadriceps que muestra desgarro fascicular marginal (flecha).

también las roturas tendomusculares completas y aquellas que se acompañan de avulsión de las inserciones óseas, situación que puede ocurrir en el tendón directo del recto anterior del cuadriceps y, en el origen de los tendones isquiotibiales. Generalmente se acompañan de hematomas de cierta magnitud y, equimosis extensas. En la fase aguda, que comprende hasta las 24 horas, el hematoma es ecogénico $y$, va perdiendo progresivamente su ecogenicidad hasta hacerse anecogénico en la fase crónica (Figuras 6 y 7 ).

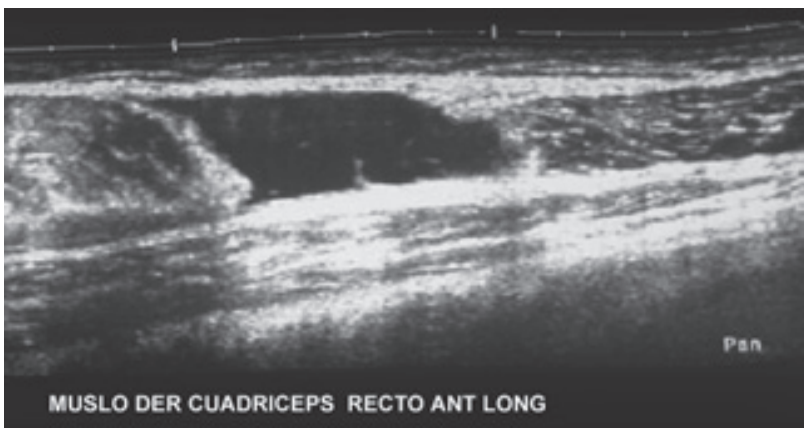

Figura 6. Desgarro muscular completo a nivel del recto anterior del cuadriceps con colección hemática en el lecho. 

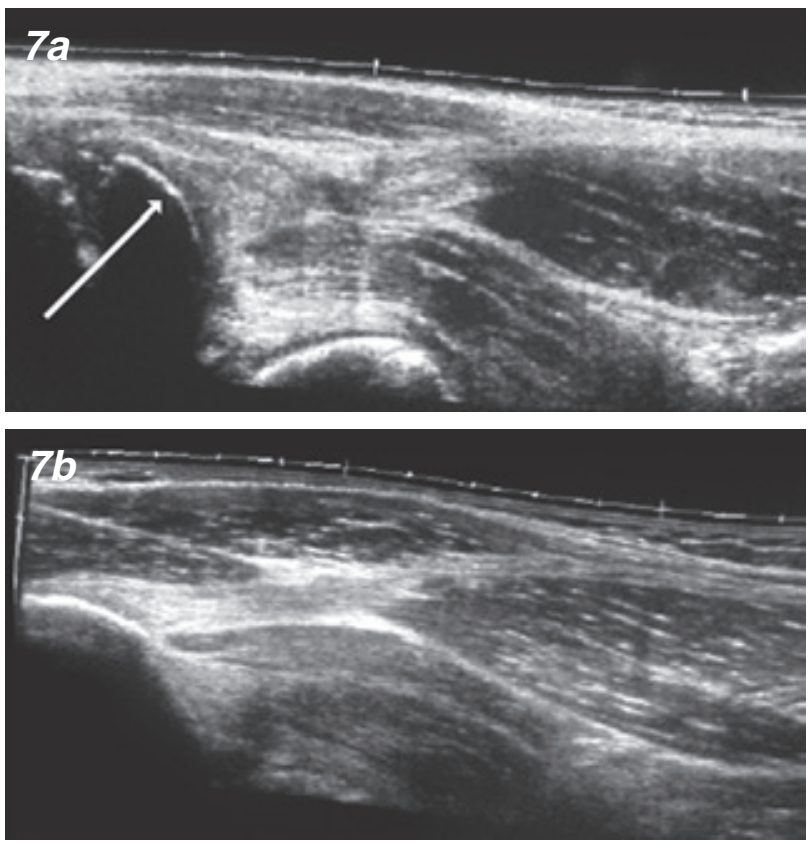

Figura 7 a,b. a: Lesión tendomuscular con avulsión de la inserción del tendón directo del recto anterior del cuádriceps (flecha). Este tipo de lesiones ocurre en pacientes jóvenes en quienes el núcleo de osificación de la espina ilíaca anteroinferior no se ha fusionado al hueso. b: Inserción normal del tendón directo del recto anterior del cuadriceps en la espina iliaca anteroinferior.

6) Adherenciolisis. Situación particular que se refiere a la apertura de la cicatriz, o redesgarro, generalmente parcial y que ocurre siempre en la zona periférica del desgarro (Figura 8).

Puede ocurrir durante el período de cicatrización al no respetarse los tiempos de reposo, caso en el cual la lesión puede ser de una magnitud incluso mayor que la original. Más frecuente es que ocurra en etapas postcicatrización, con pequeños focos de desinserción marginal de la fibrosis, debido a la interacción de un tejido elástico como lo es el músculo con un tejido rígido como lo es la fibrosis.

Esta situación es relativamente frecuente, provoca dolor local y ultrasonográficamente pueden detectarse sutiles láminas de fluido que se correlacionan con los focos de desinserción cicatricial. En ocasiones la detección suele ser difícil dentro del contexto de la cicatriz. En etapas precoces una RM puede confundir más que ayudar, ya que demostrará edema el cual suele reabsorberse en un tiempo superior a la mejoría clínica. Este tipo de lesiones se asemejan a los desgarros miofasciales.

\section{Conclusión}

Se presenta una clasificación ultrasonográfica desarrollada por el autor a lo largo de años de práctica en el área musculoesquelética, producto de la constatación de patrones repetitivos de los tipos más frecuentes de desgarros musculares que ocurren tanto en la práctica deportiva profesional como aficionada, clasificación que ha sido aceptada e incorporada en el
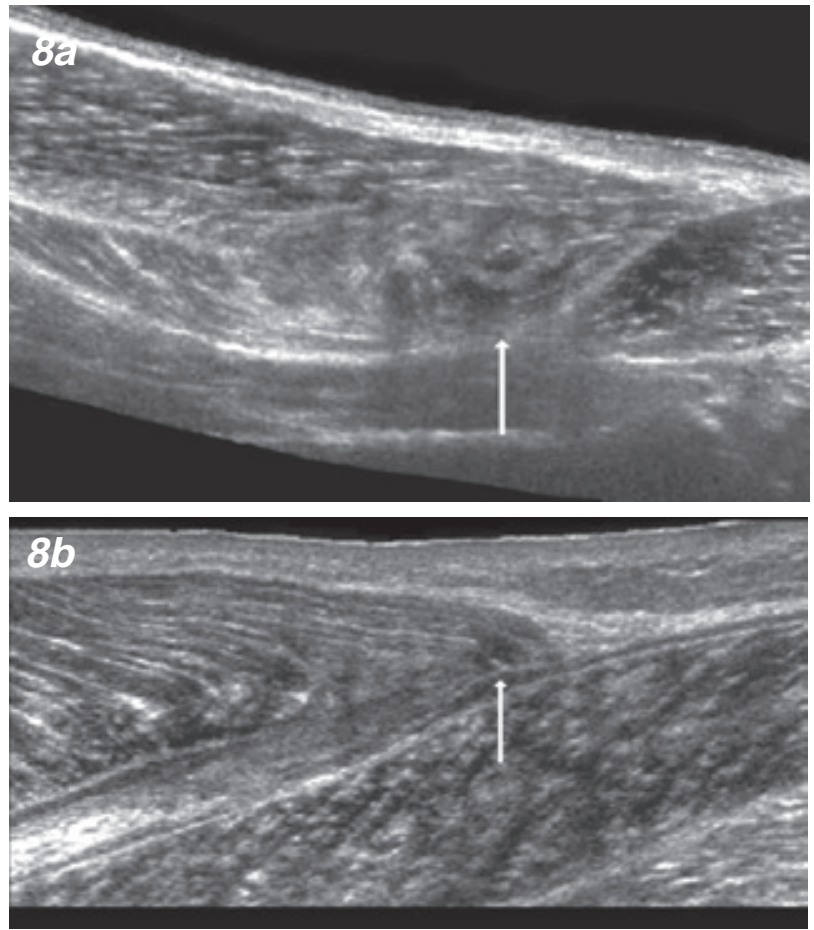

Figura 8 a,b. Adherenciolisis a: Precoz: Redesgarro marginal de cierta cuantía en un contexto cicatricial en evolución (flecha). Obsérvese la amplia zona de alteración estructural por el desgarro previo. b: Tardía: Desgarro miofascial antiguo del gemelo interno, con pequeño foco de disrupción sintomático, similar a fino desgarro miofascial, en el margen de la cicatriz (flecha).

lenguaje y manejo de los profesionales dedicados a la medicina deportiva, ya que entrega parámetros cualitativos y cuantitativos que permiten en general, establecer pautas y a la vez pronósticos de curación bastante acotados.

\section{Bibliografía}

1. Boutin R, Fritz R, Steinbach L. Imaging of sport related Injuries. Radiol Clin North Am 2002; 40: 333-362.

2. Kaplan PA, Anderson JC, Norris MA, Matamoros A Jr.. Ultrasonography of post traumatic soft-tissue lesions. Radiol Clin North Am 1989; 27: 973-982.

3. Van Holsbeeck M, Introcasso JH. Musculoskeletal Ultrasonography. Radiol Clin North Am 1992; 30: 907-925.

4. Chhem RK, Kaplan PA, Dussault RG. Ultrasonography of the musculoskeletal system. Rad Clin North Am 1994; 32 : (2) 275-289.

5. Fornage $B$. The case for ultrasound of muscle and tendons. Seminars in musculoskeletal Radiology 2000; 4: 375-392.

6. Van Holsbeeck M, Introcasso JH. Sononography of muscle, in Musculoskeletal Ultrasound, Mosby, 2nd. Ed. 2001

7. Steinbach L, Fleckenstein J, Mink J. MR imaging of muscle injuries. Seminars in musculoskeletal Radiology 1997; 1: 127-142.

8. Bergman G, Fredericson M. Magnetic resonance imaging of stress reaction, muscle injuries and other overuse injuries in runners. MR Clinics of North Am 1999; 7: 151-174.

9. May DA, Disler Dg, Jones E.A. et al. Abnormal signal intensity in skeletal muscle at MR imaging: patterns, pearls and pitfalls. In Musculoskeletal Imaging. Radiographics Special Issue 2000; 20: S295-315. 